\title{
FINITE ELEMENT ANALYSIS OF SHEAR TRANSFER OF FIBROUS CONCRETE UNDER COMPRESSIVE STRESS
}

\author{
Al-Sulaifanie, B. J.* \\ Professor \\ Al-Feel, J. R. ** \\ ept. of Civil Engineering, College of Engineering, Mosul University
}

\begin{abstract}
:
This study presents a numerical analysis of push-off and modified push-off fibrous concrete specimens. The investigated variables were, volume fraction of fibres, area of reinforcement, and the ratio of the compressive to the shear stress. Eight nodes isoparametric elements were used to represent concrete, and embedded bar elements to represent the reinforcement. The nonlinear behaviour of fibrous concrete in compression, tension and the reduction of the shear modulus due to cracking were taken into account.

The numerical results showed good agreement with the experimental results, the average ratio of the calculated to the experimental first crack shear stress is $(0.955)$, and the average ratio of the calculated to the experimental shear strength was $(0.981)$. The cracks patterns showed that the fibrous specimens have less numbers of cracks than that of plain specimens at a certain shear force, and the presence of fibres delay the initiation the cracks. The calculated slip is slightly more than the experimental slip at early stage of loading and the difference increased prior to the failure load.
\end{abstract}

Key Words: cement, contour, cracks pattern, fibres, finite element, shear transfer.

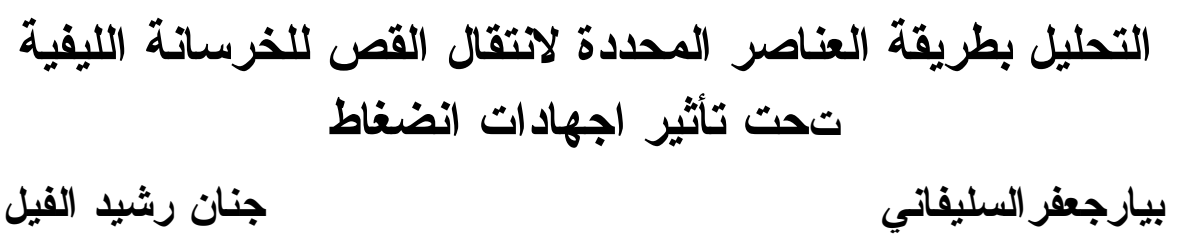

تقدم هذه الدراسة تحليلا عدديا لنماذج الافع ونماذج الافع المحورة للخرسانة الليفية. المتغيرات التي تم در استها هي

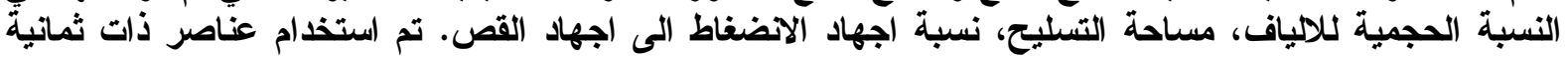
عقد لتمثيل الخرسانة وعناصر قضبان مطمورة لحديد التسليح. تم اخذ السلوك غير الخدية الخطي للخرسانة الليفية في

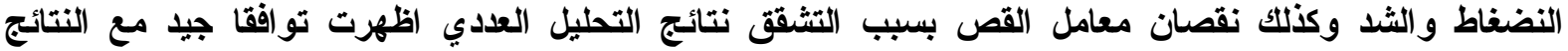
العملية، معدل نسبة النتائج العددية الى العملية لاجهادات القص فئلفي في مرحلة التشقق تساوي(0.955) وللمقاومة

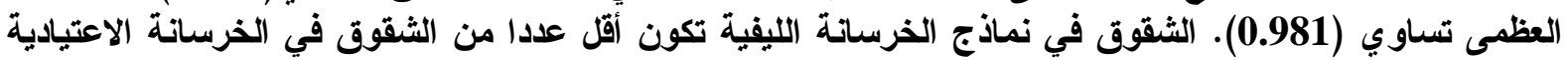

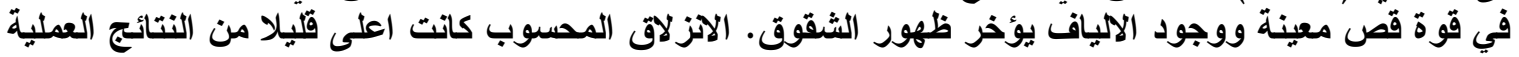

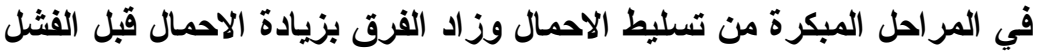




\section{INTRODUCTION:}

A shear force which is transmitted across a specific shear plane is denoted as shear transfer. Examples of such situations are precast concrete connection, brackets, corbels, members with shear span less than the effective depth where pure or direct shear is more likely to occur, column footing connections subjected to high shear forces and concrete cast at different ages, [1-3]. In some cases a crack exists in the shear plane before any shear force is applied due to either temperature deformation or due to the existence of tension forces caused by shrinkage restraint. There are two mechanisms in which the shear transfer strength may develop

For specimens with shear reinforcement normal to the shear plane with no cracks along the shear plane, the governing role in strength development is the truss action, and in case where there is a crack along the shear plane before the application of load, for specimens with reinforcement normal to the shear plane, a shear friction mechanism can be used [4].

Steel fibers enhance the tensile, flexural and shear strengths of concrete besides increasing the strain capacity under all states of stresses [5].The finite element method was used for the nonlinear analysis of fibrous concrete members, such as shallow beams, deep beam, beam-column connections, corbels, columns and slab[6,7] .

Muhoder and Meshri [7] used the finite-element method for the nonlinear analysis of push-off reinforced concrete specimens subjected to direct shear with or without lateral compressive stress. Nine-nodded, two dimensional isoparametric elements were used to represent concrete and steel. The Mohr-coulomb criterion was used as a failure envelope:

where

$$
\tau=C-\sigma_{n} \cdot \tan \phi
$$

$\tau=$ shear stress, $\sigma_{n}=$ normal stress ( tension is positive), $C=$ cohesion, $\phi=$ angle of internal friction and $\tan \phi$ taken equal to 1.4 (normal weight concrete) as recommended by the ACI Code [1]. The ratio of the test / numerical shear strength for 15 specimens ranged between 0.94 to 1.3 with a standard deviation of 0.102 . The numerical results showed that the shear stress distribution across the shear plane was intermediate between the uniform and parabolic distribution.

In this study, the main purpose is to investigate the influence of the steel fibers, reinforcement ratio, and the direct stresses on the shear transfer strength of push-off specimens by using the finite element method.

\section{FINITE ELEMENT DESCRIPTION:}

A nonlinear finite element analysis was carried out; the specimens were considered in a state of plane stress. Eight nodes isoparametric elements used to represent concrete, and embedded bar elements to represent the reinforcement.

The reinforcing bars are assumed as an axial member embedded anywhere within the element. This simulation was presented for the first time by Phillips and Zienkiewicz [8]. A perfect bond was assumed between concrete and the reinforcement. The modified NewtonRaphson algorithm is used In the present study, and the

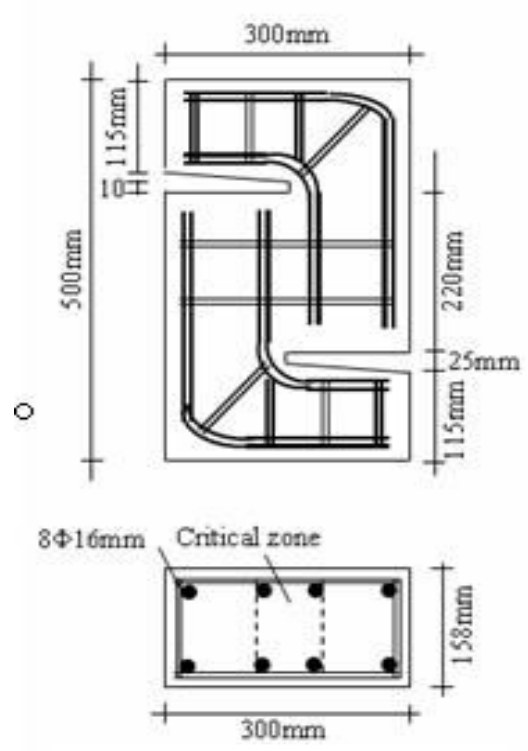

Fig. (1) Dimensions of the specimens 


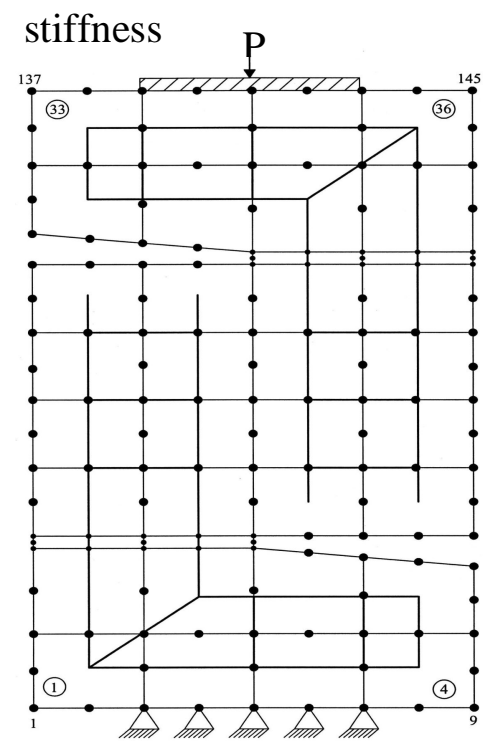

Fig. (2a): Mesh representation of the push-offspecimens

$$
(\theta=0)
$$

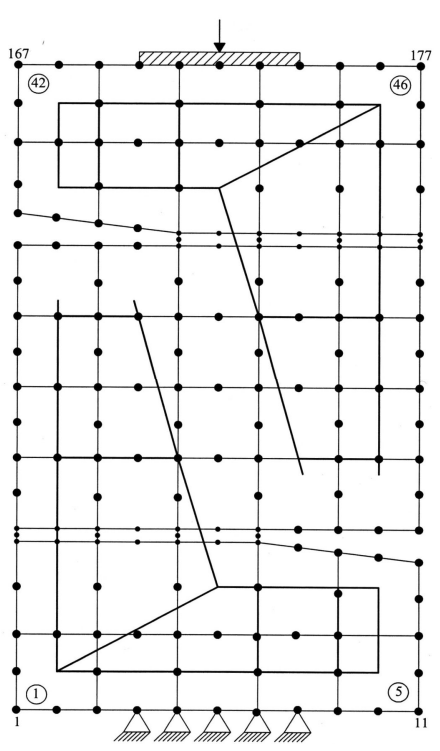

Fig. (2b) Mesh representation of the push-off specimens $\left(\theta=15.25^{\circ}\right)$

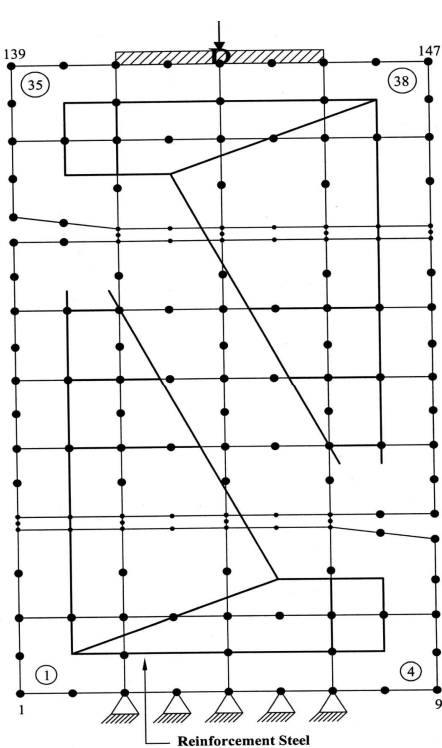

Fig. (2c): Mesh representation of the push-off specimens

$$
\left(\theta=30.5^{\circ}\right)
$$

matrix is modified in the second iteration of each load increment, a displacements convergence criterion is used.

The dimensions of the specimens is shown in Fig.(1), and Fig.(2a,b and c) show the mesh representation of the push-off specimens with three angles $\left(\square=0,15.25^{\circ}\right.$ and $\left.30.5^{\circ}\right)$. The figures show also the method of applying the loads on the specimens and the boundary conditions.

\section{MATERIALS CONSTITUTIVE RELATIONSHIPS}

The nonlinear behaviour of fibrous concrete in compression, tension and the reduction of the shear modulus due to cracking were taken into account. The materials constitutive relationships used including the uniaxial stress - strain relationships in compression and tension of the fibrous concrete and steel, biaxial behavior of the concrete, and failure criteria.

Compressive Stress-Strain Relationship: Two models are used to represent the stress-strain curve; A - elastic - perfectly plastic, where the material is assumed elastic until the effective stress reach the compressive strength of fibrous concrete. $\mathbf{B}$ - strain -hardening approach where a parabolic stress - strain curve is assumed after the effective stress reach $30 \%$ of the compressive strength followed by a parabolic stress-strain curve and until the effective stress reach the compressive strength of fibrous concrete, then a perfect plasticity is assumed until crushing occurs.

In the absence of test data the empirical equations proposed by Soroushian and Lee [9] may be used to calculate the compressive strength of fibrous concrete as follow:

$$
f_{c f}^{\prime}=f_{c}^{\prime}+3.6 \frac{V_{f} l_{f}}{d_{f}}
$$

Where: 
$f_{c f}^{\prime}=$ compressive strength of fibrous concrete $(\mathrm{MPa}), f_{c}^{\prime}=$ compressive strength of plain concrete $(\mathrm{MPa}), V_{f}=$ fibers volume fraction, and $l_{f}, d_{f}=$ length and diameter of the fibres respectively.

The strain at peak stress $\left(\mathcal{E}_{\circ f}\right)$ as given by Soroushian and Lee [9] is used in this investigation:

$\varepsilon_{\circ f}=\frac{2 f_{c}^{\prime}}{E_{c}}+0.0007 \frac{V_{f} l_{f}}{d_{f}}$

The ultimate crushing strain in compression as defined in reference [5] is used:

$\varepsilon_{\text {cuf }}=3011+2295 V_{f}$ (micro strain)

\section{Modulus of Elasticity:}

The following formula was used for the elastic modulus of plain concrete which depends on the concrete compressive strength and density [4].

$E_{c}=\left(3320 \sqrt{f_{c}^{\prime}}+6895\right)(w c / 2300)^{1.5}$

$\mathbf{w}_{\mathbf{c}}=$ concrete density in $\mathrm{kg} / \mathrm{m}^{3}$

For fibrous concrete the modulus of elasticity can be calculated from equation [10]:

$$
\mathrm{E}_{\mathrm{cf}}=\sqrt{\mathrm{E}_{90} \mathrm{E}_{\mathrm{o}}}
$$

where $E_{c f}, E_{90}$ and $E_{0}$ are secant moduli of elasticity of concrete with randomly oriented fibers, longitudinally aligned and transversely aligned fibers respectively.

$$
\begin{aligned}
& E_{o}=\frac{E_{c} E_{f}}{V_{c} E_{f}+V_{f} E_{c}} \\
& E_{90}=2\left[1-v_{f}+\left(v_{f}-v_{c}\right) v_{c}\right]\left[\frac{M_{f}\left(2 M_{c}+G_{c}\right)-G_{c}\left(M_{f}-M_{c}\right) v_{c}}{\left(2 M_{c}+G_{c}\right)+2\left(M_{f}-M_{c}\right) v_{c}}\right]
\end{aligned}
$$

where

$V_{c}$ and $V_{f}$ are volume fractions of concrete and fibers.

$G_{C}$ is concrete shear modulus.

$v_{c}$ and $v_{f}$ are the Poisson's ratio of concrete and fibres respectively.

$M_{c}=\frac{E_{c}}{2\left(1-v_{c}\right)}, M_{f}=\frac{E_{f}}{2\left(1-v_{f}\right)}$

\section{Tensile Stress - Strain Relationship:}

The stress - strain relationship of fibrous concrete in tension which is suggested in reference $[11,12]$, which can be represented by continuous function is used: 


$$
\frac{f_{t}}{f_{t f}^{\prime}}=\frac{\beta^{\prime}\left(\varepsilon / \varepsilon_{t f}\right)}{\beta^{\prime}-1+\left(\varepsilon / \varepsilon_{t f}\right)^{\beta^{\prime}}}
$$

where

$$
\begin{array}{ll}
\beta^{\prime}=1.093+0.7132 R^{2} I^{-0.926} & \text { For hooked fibres } \\
\beta^{\prime}=1.093+7.4848 R . I^{-1.387} & \text { For smooth fibres } \\
\beta=0.5811+1.093 R . I^{-0.7406} & \text { For crimped fibres } \\
R . I=W_{f} l_{f} / d_{f} &
\end{array}
$$

Where

R.I is a reinforcing index and $W_{f}$ is the weight fraction of the fibres. The tensile strain $\varepsilon_{\mathrm{tf}}$ at peak tensile stress $f_{t f}^{\prime}$ for fibrous concrete can be defined as proposed by Lee and Soroushian [9] are used in the present study as follow:

$$
\begin{aligned}
& f_{t f}^{\prime}=f_{t}^{\prime}\left(1+0.016 N_{f}^{1 / 3}+0.05 \pi d_{f} l_{f} N_{f}\right) \\
& \varepsilon_{t f}^{\prime}=\varepsilon_{t}\left(1+0.35 N_{f} d_{f} l_{f}\right)
\end{aligned}
$$

where

$f_{t}^{\prime}=$ tensile strength of plain concrete. $\boldsymbol{\varepsilon}_{\mathbf{t}}=$ matrix cracking strain.

$N_{f}=$ Number of fibres per unit cross section area:

$N_{f}=\eta_{0}\left(4 V_{f} / \pi d_{f}^{2}\right)$

$\eta_{0}=$ Orientation factor, in the present study the value of $\eta_{0}$ used equal to 0.41 [13].

\section{THE YIELD CRITERIA}

Many yield criterions were proposed $[14,15]$ to define the plastic stage. In the present study the following yield function is used, which is adopted in many nonlinear analysis of concrete structures:

$$
f\left(I_{1}, J_{2}\right)=\left[\beta_{f}\left(3 J_{2}\right)+\alpha_{f} I_{1}\right]^{0.5}=\sigma_{o}
$$

where $\alpha_{f}$ and $\beta_{f}$ are material parameters and $\boldsymbol{\sigma}_{\mathbf{o}}$ is the uniaxial compressive strength. The material parameters have been obtained by Abdul- Razzak [5]:

$$
\begin{gathered}
\alpha_{f}=\frac{1-\omega^{2}}{\omega^{2}-2 \omega} \sigma_{o} \\
\beta_{f}=\frac{1-2 \omega}{\omega^{2}-2 \omega}
\end{gathered}
$$

Where $\omega=e^{x}$.

The two dimensional stress representation [16] (biaxial compression-compression region) of fibrous concrete model is shown in Fig. (3). In the tension- compression zone, the tensile strength of fibrous concrete is predicted from a parabolic relation which was proposed by $\mathrm{Al}-$ Ta' an and Mahmood [17] as shown in Fig. (4) and is given by: 
$\frac{\sigma_{2}}{f_{c f}^{\prime}}+s^{2}\left(\frac{\sigma_{1}}{f_{c f}^{\prime}}\right)^{2}=1$

Equation (19) can be rewritten to give the peak compressive strength $\sigma_{2 p}$ as a function of the uniaxial compressive strength $f_{c f}^{\prime}$, ratio of uniaxial compressive strength to its uniaxial tensile strength $\mathbf{s}$, and the stress ratio $\alpha_{2}$ as:

$\sigma_{2 p}=\left[\frac{\sqrt{1+4\left(\alpha_{2}^{2} s^{2}\right)}-1}{2\left(\alpha_{2}^{2} s^{2}\right)}\right] f_{c f}^{\prime}$

and the peak tensile strength as:

$\sigma_{1 \mathrm{p}}=\sigma_{2 \mathrm{p}} \alpha_{2}$

$\sigma_{1 \mathrm{P},} \sigma_{2 \mathrm{P}}$ are the limiting principal tensile and compressive strength respectively.

$$
\sigma_{1} / f_{\mathrm{cf}}^{\prime}
$$

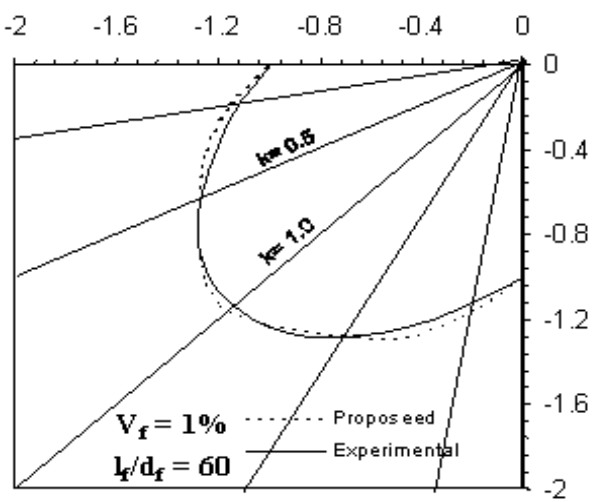

Fig. (3) Present model FRC for biaxial compression - compression. region 「16

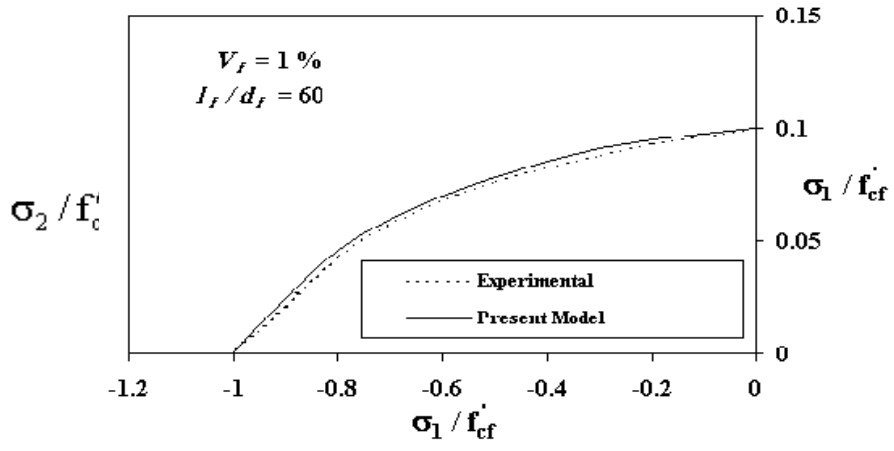

Fig. (4) Envelope for biaxial tension - compression [17]

\section{RESULTS AND DISCUSSION}

The properties of concrete used in tension and compression were taken from the experimental test results [18]. The cubes strength of plain and fibrous concrete was multiplied by 0.8 to obtain the equivalent cylinder strength, and the splitting strength also multiplied by 0.8 to get the direct tensile strength. Because the specimens were skew symmetry, it was necessary to analyze the entire specimen. The mesh used is shown in Fig. (2) for $\square=0$, $15.25^{\circ}$, and $30.5^{\circ}$. Poisson's ratio was taken equal to 0.2 . The steel properties used are shown in Table (1) for the longitudinal and transverse shear reinforcement [18].

Table (1): Properties of the Used Reinforcement

\begin{tabular}{|l|l|l|l|}
\hline $\begin{array}{l}\text { Diameter } \\
(\mathrm{mm})\end{array}$ & Location & $\begin{array}{l}\text { Yield strength } \\
(\mathrm{MPa})\end{array}$ & $\begin{array}{l}\text { Tensile strength } \\
(\mathrm{MPa})\end{array}$ \\
\hline 16 & Longitudinal & 437 & 730 \\
\hline 6 & Stirrups & 510 & -------- \\
\hline 10 & Stirrups & 321 & 438 \\
\hline
\end{tabular}

1-Shear Transfer Strength 
Table (2) shows comparison of the finite element results with the experimental results [18] of shear strength for the push-off specimens. The numerical results showed a very good agreement with the test results for all specimens. The ratio of $\left(\mathrm{v}_{\mathrm{u}}\right.$ cal.) to $\left(\mathrm{v}_{\mathrm{u}}\right.$ exp.) range from (0.89-1.08) with an average value of (0.981), standard deviation $(\mathrm{SD})=0.0485$ and a coefficient of variation of $4.9 \%$.

Table (2) Comparison of the Numerical and Experimental Results Of Shear Strength for Pushoff Specimens

\begin{tabular}{|l|l|l|l|l|l|l|}
\hline \multirow{2}{*}{$\begin{array}{l}\text { Specimen } \\
\text { No. }\end{array}$} & $\begin{array}{l}\text { Shear plane } \\
\text { length(mm) }\end{array}$ & $\begin{array}{l}\text { No.and } \\
\text { dia. } \\
\text { of stirrups }\end{array}$ & $\begin{array}{l}\text { Fibres } \\
\text { volume }\end{array}$ & $\begin{array}{l}\text { F.E. } \\
\text { Shear strength } \\
\text { MPa }\end{array}$ & $\begin{array}{l}\text { Experimental } \\
\text { Shear strength } \\
\text { MPa[18] }\end{array}$ & $\begin{array}{l}\mathrm{v}_{\mathrm{u}} \text { cal/ } \\
\mathrm{v}_{\mathrm{u}} \text { exp }\end{array}$ \\
\hline A1 & 220 & 0 & 0 & 4.83 & 4.95 & 0.98 \\
\hline A2 & 230 & 0 & 0 & 8.59 & 8.82 & 0.97 \\
\hline A3 & 255.5 & 0 & 0 & 13.57 & 13.02 & 1.04 \\
\hline A4 & 220 & 0 & 0.5 & 5.50 & 5.20 & 1.06 \\
\hline A5 & 230 & 0 & 0.5 & 9.25 & 9.32 & 0.99 \\
\hline A6 & 255.5 & 0 & 0.5 & 14.26 & 15.17 & 0.94 \\
\hline A7 & 220 & 0 & 1.0 & 6.49 & 6.55 & 0.99 \\
\hline A8 & 230 & 0 & 1.0 & 10.60 & 11.16 & 0.95 \\
\hline A9 & 255.5 & 0 & 1.0 & 15.11 & 15.38 & 0.98 \\
\hline A10 & 220 & 0 & 1.5 & 6.40 & 6.27 & 1.02 \\
\hline A11 & 230 & 0 & 1.5 & 10.60 & 11.23 & 0.94 \\
\hline A12 & 255.5 & 0 & 1.5 & 15.87 & 15.90 & 1.00 \\
\hline B1 & 220 & $3-6 \mathrm{~mm}$ & 0 & 6.44 & 6.63 & 0.97 \\
\hline B2 & 230 & $3-6 \mathrm{~mm}$ & 0 & 11.22 & 11.37 & 0.99 \\
\hline B3 & 255.5 & $3-6 \mathrm{~mm}$ & 0 & 14.70 & 13.61 & 1.08 \\
\hline B4 & 220 & $3-6 \mathrm{~mm}$ & 0.5 & 6.50 & 6.90 & 0.94 \\
\hline B5 & 230 & $3-6 \mathrm{~mm}$ & 0.5 & 11.88 & 11.75 & 1.01 \\
\hline B6 & 255.5 & $3-6 \mathrm{~mm}$ & 0.5 & 15.85 & 16.02 & 0.99 \\
\hline B7 & 220 & $3-6 \mathrm{~mm}$ & 1.0 & 7.50 & 8.04 & 0.93 \\
\hline B8 & 230 & $3-6 \mathrm{~mm}$ & 1.0 & 12.50 & 11.75 & 1.06 \\
\hline B9 & 255.5 & $3-6 \mathrm{~mm}$ & 1.0 & 16.84 & 17.13 & 0.98 \\
\hline B10 & 220 & $3-6 \mathrm{~mm}$ & 1.5 & 8.06 & 8.96 & 0.90 \\
\hline B11 & 230 & $3-6 \mathrm{~mm}$ & 1.5 & 12.50 & 11.75 & 1.06 \\
\hline B12 & 255.5 & $3-6 \mathrm{~mm}$ & 1.5 & 18.80 & 18.34 & 1.02 \\
\hline C1 & 220 & $2-10 \mathrm{~mm}$ & 0 & 8.85 & 8.86 & 1.00 \\
\hline C2 & 230 & $2-10 \mathrm{~mm}$ & 0 & 11.56 & 12.63 & 0.92 \\
\hline C3 & 255.5 & $2-10 \mathrm{~mm}$ & 0 & 16.10 & 16.02 & 1.00 \\
\hline C4 & 220 & $2-10 \mathrm{~mm}$ & 0.5 & 8.91 & 9.47 & 0.94 \\
\hline C5 & 230 & $2-10 \mathrm{~mm}$ & 0.5 & 12.33 & 12.90 & 0.96 \\
\hline C6 & 255.5 & $2-10 \mathrm{~mm}$ & 0.5 & 16.8 & 16.40 & 1.02 \\
\hline C7 & 220 & $2-10 \mathrm{~mm}$ & 1.0 & 8.90 & 9.60 & 0.93 \\
\hline C8 & 230 & $2-10 \mathrm{~mm}$ & 1.0 & 13.10 & 14.58 & 0.90 \\
\hline C9 & 255.5 & $2-10 \mathrm{~mm}$ & 1.0 & 18.90 & 18.40 & 1.03 \\
\hline C10 & 220 & $2-10 \mathrm{~mm}$ & 1.5 & 9.00 & 10.10 & 0.89 \\
\hline C11 & 230 & $2-10 \mathrm{~mm}$ & 1.5 & 13.87 & 14.72 & 0.94 \\
\hline C12 & 255.5 & $2-10 \mathrm{~mm}$ & 1.5 & 19.30 & 19.18 & 1.01 \\
\hline
\end{tabular}


Fig. (5) shows comparison of the first crack shear stress of the experimental and numerical results for group A, with $(\square=0)$ for fibres percentage of 0 , $0.5,1$ and 1.5. The figure shows that the experimental results are in close agreement with the numerical results. The average of the calculated to the experimental first crack shear stress is 0.955 .

\section{2-Effect of Reinforcement Parameter}

The effect of the reinforcement parameter $\rho$ fy on the shear strength is shown in Table (2) for fibres percentages of $(0,0.5,1$, and 1.5$)$.The

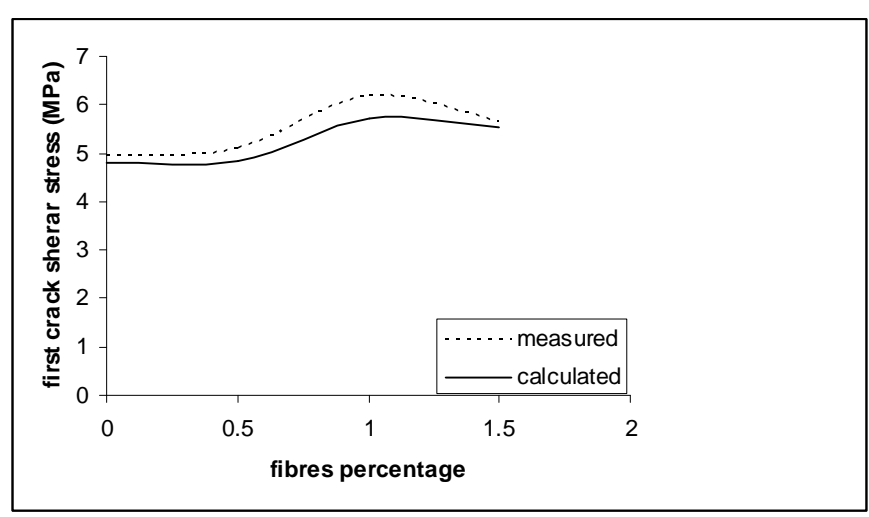

Fig. (5) Comparison of experimental and calculated first crack shear stress for Push-off specimens A1, 4, 7and 10 results show that the shear strength increases with the reinforcement parameter for all fibres percentages.

\section{3-Effect of Steel Fibres}

Table (2) shows that the ultimate shear strength increased with the fibres volume increase in the specimens with or without stirrups. The results showed that sometimes fibres was as effective as stirrups in increasing the shear strength ,the same results obtained for all specimens.

\section{4- Shear Stress Distribution}

To show the distribution of the shear stress across the shear zone, contour of the shear stresses are plotted for selected specimens to show the fibres effect on the shear stress distribution. Fig. (6) shows the shear stress contours and shear stress distribution across the shear plane of specimen A1 (without fibres). The figure shows that the shear stresses are concentrated near the slots (at the shear zone boundaries) and decreased toward the center of
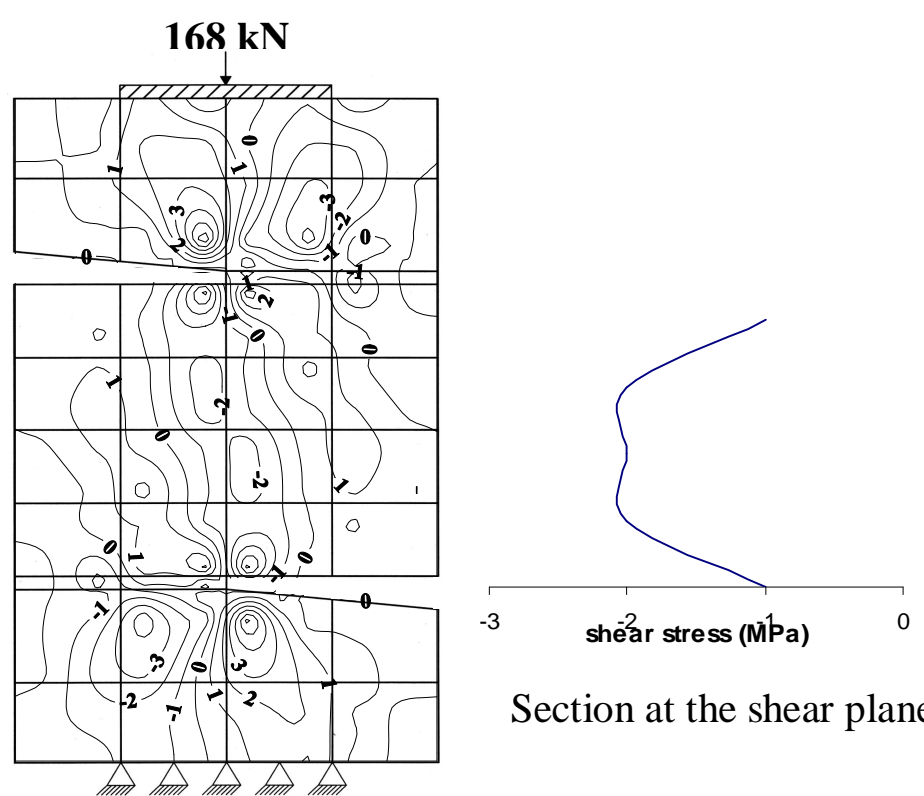

Section at the shear plane

Fig. (6) Contour of the shear stresses of push - off Specimen $A 1 V_{f}=0, \theta=0$ the shear plane. 
Fig. (7) shows the shear stresses contour for specimen A7 $\left(\mathrm{V}_{\mathrm{f}}=1 \%\right)$ for loads $192 \mathrm{kN}$ and $224 \mathrm{kN}$ respectively. The two figures have the same trend of the shear stress distribution, except that the shear stress is higher for higher load $(224 \mathrm{kN})$. The figures show also the shear stress distribution along the shear plane .
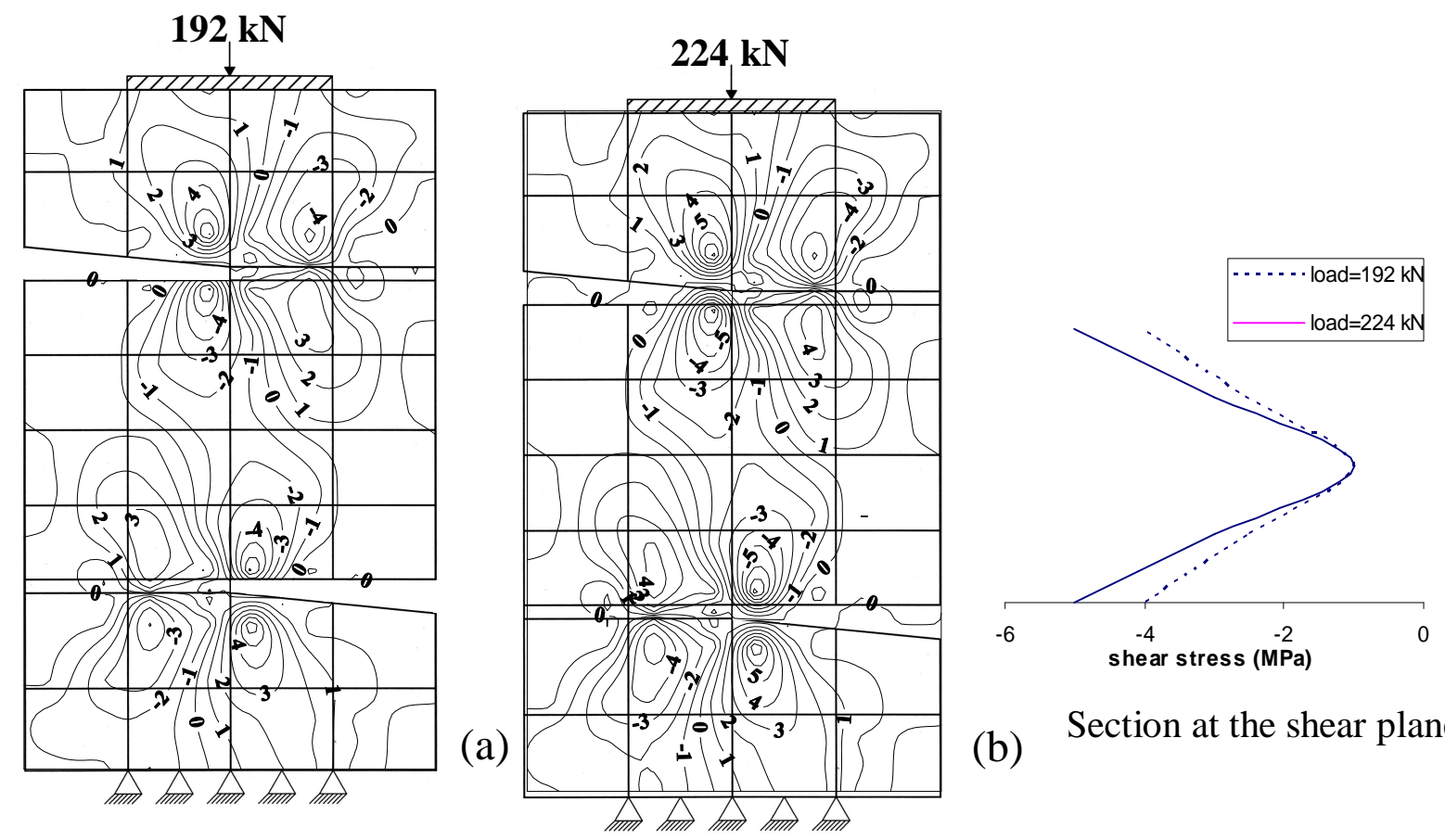

(a)

Section at the shear plane

Fig. (7) Contour of shear stresses of push - off specimen A7

$$
\mathrm{V}_{\mathrm{f}}=1 \%, \theta=0
$$

Fig. (8) Shows the contour of the shear stresses for specimens A2 $\left(\mathrm{Vf}=0\right.$ and $\left.\Theta=15.25^{\circ}\right)$ the figure shows that the contour of the shear stress is the same as that of specimen A1 Fig. (6), but the shear stress along the shear plane is slightly different, this may be attributed to the lateral compressive stress. Fig. shows the contour of the shear stresses for specimen A8 $\left(\mathrm{V}_{\mathrm{f}}=\right.$ $1 \%$ ), the figure shows that the maximum shear stress increased near the slots and decreased toward the center of the shear plane.

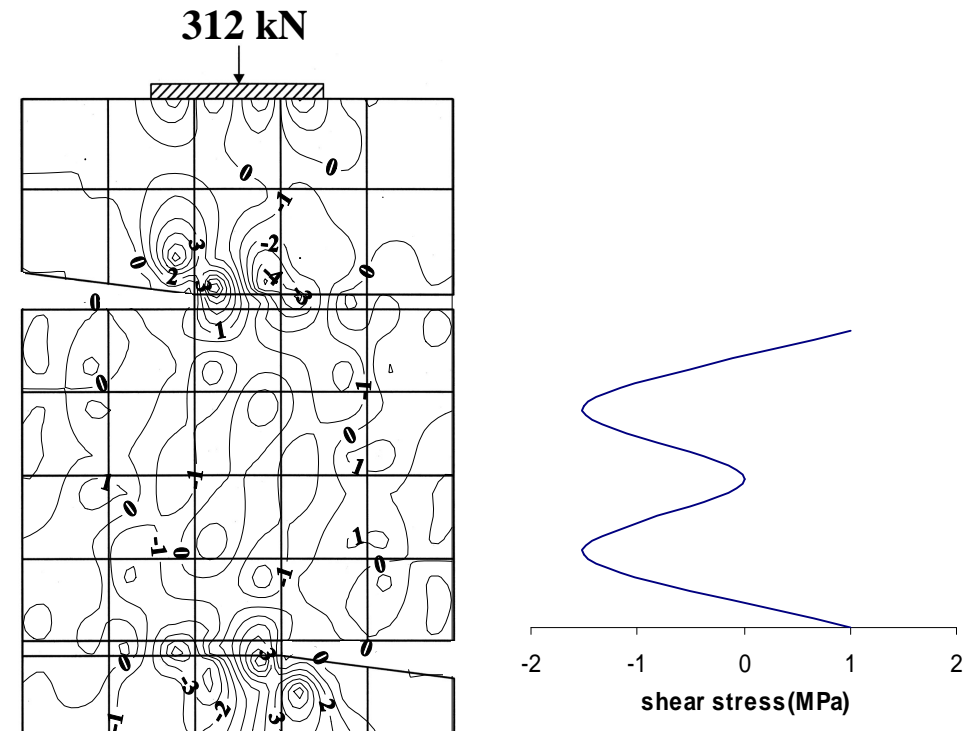

Section at the shear plane

Fig. (8) Contour of the shear stresses of push - off specimen $A 2, V_{f}=0$, 


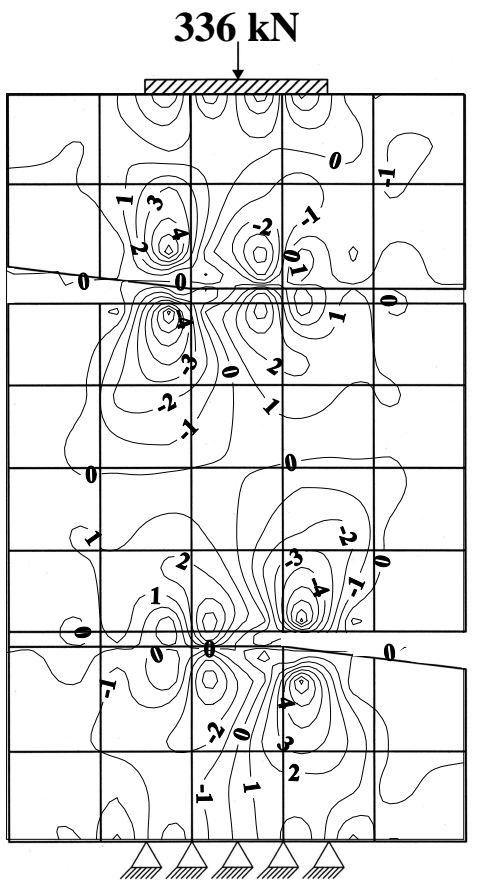

Fig. (9) Contour of the shear stress of push - off specimens

$$
\mathrm{A} 8, \mathrm{~V}_{\mathrm{f}}=1 \%, \theta=15.25^{\circ}
$$

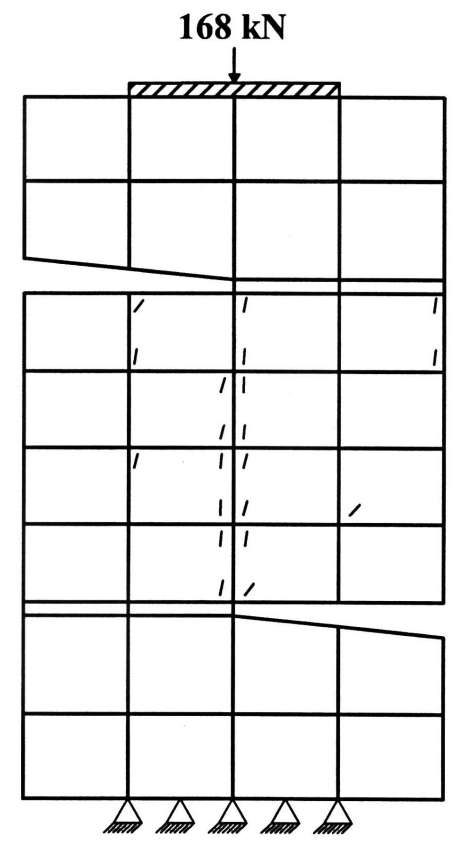

Fig. (10) Cracks pattern of specimen $\mathrm{A} 1, \mathrm{~V}_{\mathrm{f}}=0$

\section{5- Cracks Patterns}

The cracks were drawn at the mid position only (between the two slots) for selected specimens to show the fibres effect on the initiation and propagation of cracks.

Fig.(10) shows the cracks pattern of the push-off specimen A1 (plain) at a load of 168 $\mathrm{kN}$, the figure shows that the cracks occur along the shear plane with inclination that ranges between $\left(53-89^{\circ}\right)$. Fig. (11) shows the cracks pattern for push-off specimen A4 $\left(\mathrm{V}_{\mathrm{f}}=0.5 \%\right)$ at a loads of $168 \mathrm{kN}$ and $192 \mathrm{kN}$ respectively.

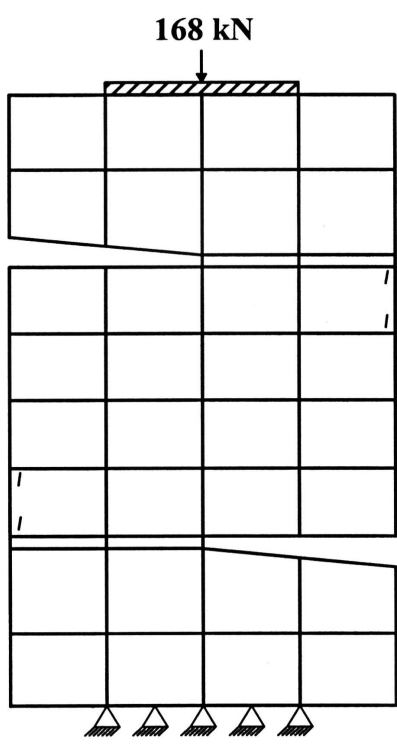

(a)

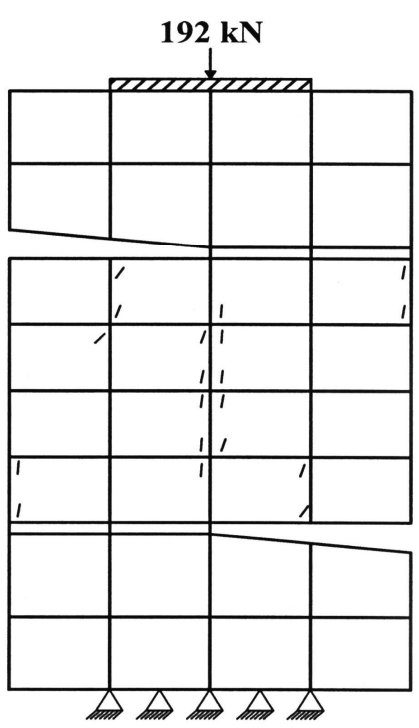

(b)

Figs.(11) Cracks pattern of specimen $A 4, V_{f}=0.5$ 
The figure shows that the cracks did not appear along the shear plane at the load of $168 \mathrm{kN}$ but appeared at load of $192 \mathrm{kN}$ with inclination that range between $\left(57-86^{\circ}\right)$. This indicates that the fibres retarded the appearance of cracks. Since the upper and lower portion of the specimens act as a cantilever, so small moment will be developed which cause tensile stress, Fig.(11a) and this interpret the appearance of the cracks.

Fig.(12) shows the cracks for specimen A2(plain) with $\theta=15.25^{\circ}$ the cracks pattern compared with the specimen which have the same $\theta$, A11(1.5\% fibre), Fig.(13) the figures show few cracks appeared at a load of $360 \mathrm{kN}$ and increased at a load of $384 \mathrm{kN}$.

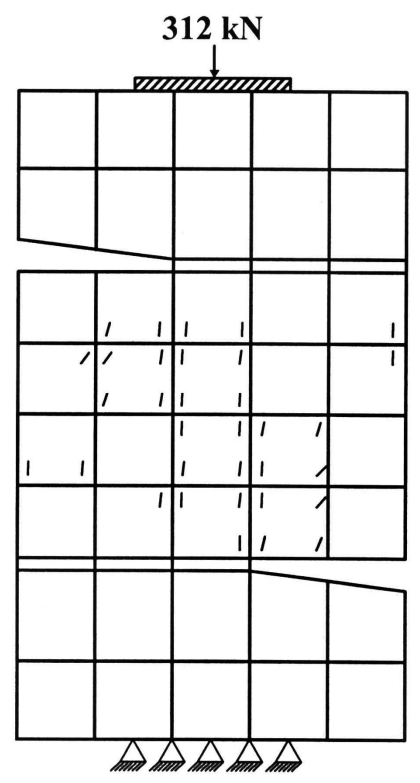

Fig.(12) Cracks pattern of specimen $\mathrm{A} 2, \mathrm{~V}_{\mathrm{f}}=0$

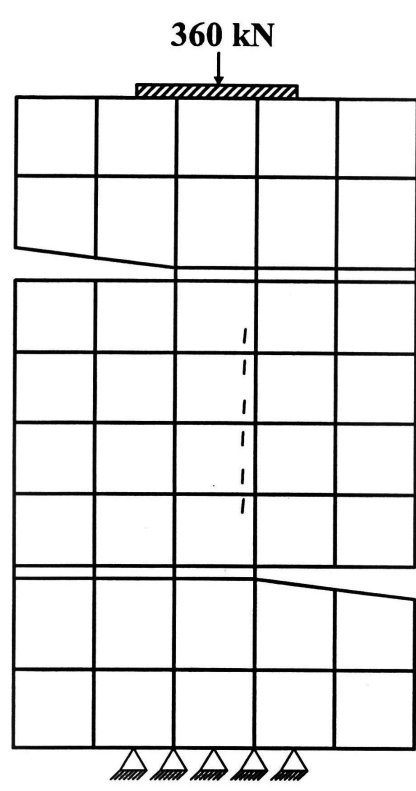

(a)

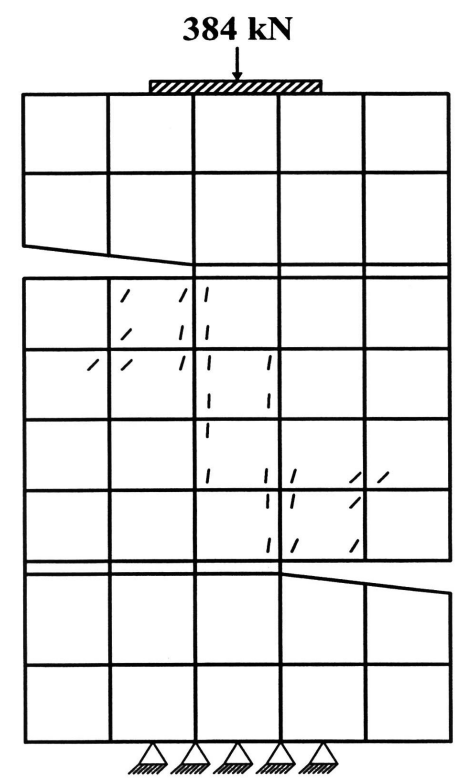

(b)

Fig.(13): Cracks pattern of specimen $\mathrm{A} 11, \mathrm{~V}_{\mathrm{f}}=1.5$

\section{6- Slip}

The slips of selected specimens were presented below. Fig.(14) shows the slip of specimen A10 $\left(\mathrm{V}_{\mathrm{f}}=1.5\right)$. The figure shows that the calculated slip is close to the experimental slip at early stage and slightly differ at failure, this variation may be attributed to the representation of the shear reinforcement in the finite element method which is represented by a line element with axial stiffness only and differ from the actual shear reinforcement. Fig.(15) shows the slip of specimen $\mathrm{C} 10$, the figure shows that the calculated slip is slightly differ from the experimental slip, this may be due to the same reason as for specimen A10, that is the representation of the shear reinforcement. 


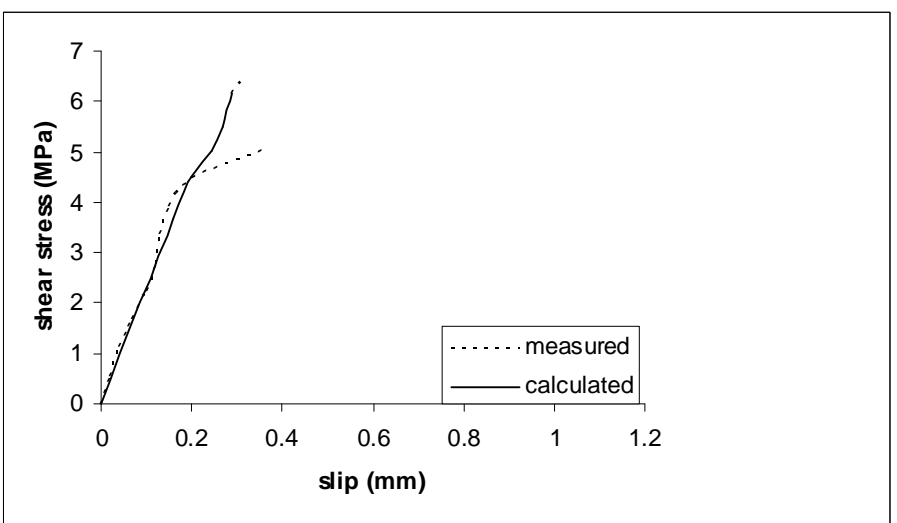

Fig. (14): Shear stress- slip for specimen $\mathrm{A} 10\left(\mathrm{~V}_{\mathrm{f}}=1.5 \%\right)$

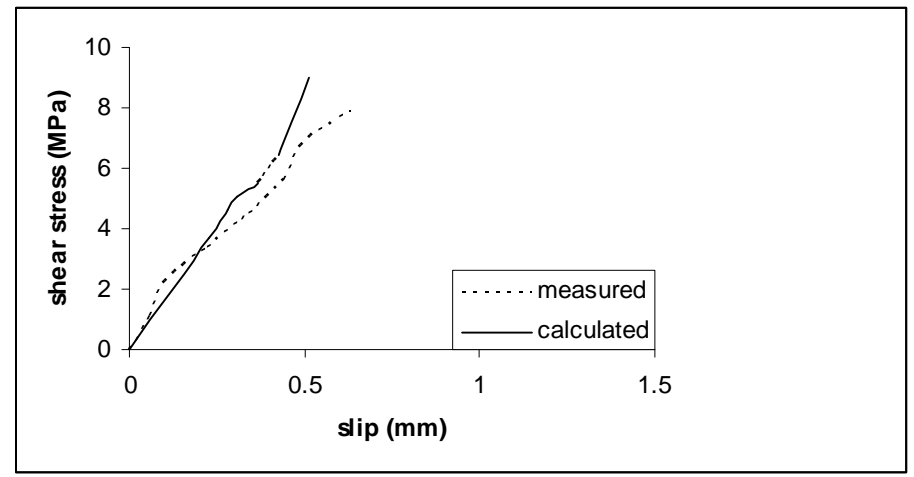

Fig.(15) shear stress-slip for specimen $\mathrm{C} 10(\mathrm{Vf}=1.5 \%)$

\section{CONCLUSIONS}

1- The finite element results of the first cracking and the ultimate shear stress showed good agreement with the experimental results, the average ratio of the calculated shear strength to the experimental shear strength was (0.9814).

2- The distribution of the shear stress of the push-off specimens is maximum at the ends of the shear plane and decreased towards the centre.

3- The predicted slip of specimens without shear reinforcement push-off results showed good agreement with the experimental slip, while the slip of specimens with shear reinforcement slightly differs from the experimental slip.

4. The cracks initiation and propagation pattern showed a realistic sequence.

5. The nonlinear finite element analysis can be used to trace the behaviour of shear transfer specimens and can be used for a parametric study.

\section{REFERENCES}

[1]. ACI Committee 318 M-02, "Building Code Requirements for Structural Concrete", Farmington Hills, Michigan, 2002, 443pp.

[2]. Nawy, E. G., "Reinforced Concrete: A Fundamental Approach", Prentice hall, Pearson Education, Inc., Fifth edition, 2003, 821pp.

[3]. Wang, C. K. and Salmon, C. G., "Reinforced Concrete Design", Harper and Row Publishers, New York, Fourth edition, 1985, 947 pp.

[4]. Nilson, A. H., Darwin, D. and Dolan, C. W., "Design of Concrete Structures", Mc-Graw Hill Book company, 2003, 779 pp. 
[5]. Abdul-Razzak, A. A., "Nonlinear Finite Element Analysis of Fibrous Fibrous Reinforced Concrete Structural Members, Ph. D. Thesis, 1996, University of Mosul,

[6]. Al-Ta'an, S. A. and Abdul Razzak, A. A., "Nonlinear Finite Element Analysis of Fibrous Reinforced Concrete Corbels", Al-Rafidain Engineering Jour., Vol. 11, No. 1, 2003, pp. 3446.

[7]. Mohuder, S. H. and Meshri, M. A., "Study of Shear Transfer in Reinforced Concrete Members by Finite Element Method", Scientific Jour. of Tikrit University, Engineering Sciences, Vol. 8, No.1, 2001, pp.12-37.

[8]. Phillips, D.V. and Zienkiewicz, O.C., "Finite Element Nonlinear Analysis of Concrete Structures", Proc. of the Inst. Civil Eng., Part 2, Vol. 61, 1976, pp. 59-88.

[9]. Soroushian, P., and Lee,C. D., "Constitutive Modelling of Steel Fibre Reinforced Concrete under Direct Tension and Compression", Proc. of the Inter. Conf. on Recent Developments in Fibre Reinforced Cement and Concrete ,Cardiff, U.K., Eds. Swamy and Barr, 1989, pp.363- 377.

[10]. Shah, S. P. and Rangan, B.V., " Fiber Reinforced Concrete Properties", ACI Jour., Vol. 68, No. 2, 1971, pp. 126-135.

[11]. Al-Nakkar, B. S. P., "Nonlinear Finite Element Analysis of Fibrous Reinforced Concrete Frames under Cyclic Loading", M.Sc. Thesis, Mosul University, 2002, 116 pp.

[12]. Al-Hasan, B. A. " Nonlinear Finite Element Analysis of Partially Prestressed Fibrous Concrete Beams", M. Sc. Thesis, Mosul University, 2004, 127 pp.

[13]. Romuldi, J. P. and Mandel ,J. A., "Tensile Strength of Concrete Affected by Uniformly Distributed Closely Spaced Short Length of Wire Reinforcement", ACI Jour., Vol. 61, No. 6, 1964, pp. 657-671.

[14]. Owen,D.R.J. and Hinton, E. , "Finite Element in Plasticity: Theory and Practice ", Pinneridge Press, Swansea ,U.K., 1980

[15]. Chen, W. F., "Plasticity in Reinforced Concrete ", Mc-Graw Hill Book Company, 1982.

[ 16]. Yin, W. S. ,Eric, C. M. Su, Mansur ,M. A. and Hsu ,T.C., "Biaxial Tests of Plain and Fiber Concrete ", ACI Materials Jour., Vol. 86, No. 3, 1989, pp. 236-243.

[17]. Al-Ta'an, S. A. and Mahmood, M. N., "Biaxial Stress-Strain Relationships for Concrete", Proc. of the Second Inter. Conference on the Applications of Computers in Concrete, Singapore, Vol. 1, 1988, pp. C1-C14.

[18] .Al-Feel, J.R., 'Experimental and Numerical Investigation of Shear Transfer with Direct Stress in Steel Fibre Reinforced Concrete “, Ph.D. Thesis, 2006, University of Mosul. 